\title{
God as World-Mind: Some Theological Implications of Panpsychism
}

\author{
David Skrbina
}

Perhaps the two most important concepts in the history of philosophy are God and mind. Unsurprisingly, both are notoriously vague, which is a large part of the reason why there has been such a diversity of views on these topics. Needless to say, the literature on each is vast. Less examined, though, is the intersection of these two concepts. >God as mind $<$; >mind as God «-what can these mean? What do they imply? How can such hybrid concepts be articulated and integrated into the current stream of philosophic thought? These are the questions that I will explore in the present essay. Ultimately I will argue that the most reasonable conception of God is that of a world-mind-the mind of the cosmos - in a sense that is completely analogous to the mind of a human being.

These questions will be examined in light of two other over-arching concepts: panpsychism and panentheism. Rather than analyzing these in terms of their various and subtle forms, I will address each in a relatively broad and loose conception. Panpsychism I take to be the view that all objects, or systems of objects, have, or contain, aspects of mind. Panentheism I take to be the view that God resides >in< the universe as its spirit or soul. Both of these require some discussion before moving on to the primary subject at hand.

First, panpsychism: This is an ancient and respected metaphysical view, dating to the earliest days of Western philosophy. It almost certainly derives from even older pre-rational animistic traditions, which became formalized in the language and concepts of true philosophy. Primitive peoples seemed to have had an instinctive awareness that the world of nature was suffused with agency, potency, experientiality, and will. Non-human life forms clearly worked toward desired ends in a deliberate and quasi-conscious manner. They clearly experienced the world; they could flourish and be happy; they could suffer and perish. Indigenous people, seeing themselves as fully integrated into nature and not yet as a thing apart, would certainly have viewed other animals as fully enminded. Plants, as living and growing things, also would have undoubtedly been imbued with agency and spirit. And lacking any scientific notion of life, non-living things that exhibited power, motive force, or even patterned behavior would also have been assumed to possess something like a spirit or 
soul, on a par with plants and animals. For our distant ancestors, all the world was alive.

As philosophy emerged, this ancient animistic intuition became subject to rational analysis - and thus transformed in the process. For the Greeks, the power to cause motion, or of self-motion, was a clear marker of an innate psyche. For Thales, even the humble magnetic rock was ensouled because it could move bits of iron. For others, the rational and orderly movement of celestial bodies was proof of ensoulment. Yet others saw elemental forces like fire and air as evidence of a universal psychic power. Even change itself, ubiquitous in nature, was seen as something god-like and divine-evidence of reason in nature.

Over time, arguments for panpsychism evolved in form and complexity, but never faded away. Some philosophers argued on a basis of ex nihilo, nihil fit: nothing in the effect that is not in the cause. If ensouled animals and plants could arise from mere matter, then mere matter must be ensouled. Some argued from a theological basis; if God made all and is, in some sense, extant in all things, then mind or spirit must be omnipresent. Other philosophers took cues from scientific reasoning. For example, the dynamic sensitivity of even the simplest forms of matter suggests an inherent experientiality. Yet others said that the physical manifestation of things is simply their exterior; they must also have an interior, and the best candidate for such an interior is something mind-like.

Present-day arguments are more sophisticated but draw on the same basic intuitions. We now have Russellian (in reality, Schopenhauerian) monism, analytical non-emergence arguments, process-based approaches, and a priori claims based on quasi-idealist views. Some current forms of panpsychism emphasize the mentality, consciousness, or experientiality of all (or at least some) elementary particles or ultimate entities. This is a necessary but not sufficient condition, however, because we are also compelled to accept our own enmindedness. Those who promote variations on such a micro-psychism paint for us a strange cosmos, one in which (say) atoms, humans, and perhaps >higher animals are experiential beings - and nothing else. An odd universe, to say the least. Far more likely, and more in line with historical thinking, is to argue that all physical objects, and perhaps all systems of objects, have an experiential unity or aspect. For present purposes, I will defend panpsychism in this latter sense: as a broadly conceived notion that all things have an experiential unity, a mind.

Regarding panentheism, we can date the origin of the term to the early 1800 s in the work of Karl Krause, a relatively minor German philosopher who 
studied under Schelling and Hegel. ${ }^{1}$ Krause held an organismic view of the universe, one in which God was, in effect, the soul of the physical cosmos. An omnipresent God saturated all aspects of the physical world - just as water might saturate a sponge-but remained ontologically distinct. The water is not the sponge, and God is not the universe, as pantheism would have it. Panentheism attempts to retain something of a theological God while naturalizing him; he is no supernatural being, dwelling in some otherworldly heaven. ${ }^{2}$ Krause's was an attempt to construct a modern, scientific, and naturalistic cosmos without abandoning God.

But from a present-day perspective we can see some immediate problems here. If a panentheistic God is ontologically distinct from the physical realm, we are dealing with a form of dualism. And if this God has any causal power in the world, or reacts in any way to our pleadings, we are directly faced with the severe problem of interactionism - of how a non-physical God can causally interact with physical beings or a physical universe. We are furthermore confronted with the striking lack of evidence; if such a God exists, why is he not transparently obvious to all? On the contrary, he is defended by a vanishingly small portion of humanity. ${ }^{3}$ Additionally, we need to inquire whether a panentheistic God is anything like the Christian God: specifically, one who is good, just, merciful, and loving. Any such moral God immediately runs afoul of the Problem of Evil: why would any all-powerful and all-good deity allow rampant pain and suffering? This problem has long been recognized to have no cogent reply. Responses such as Plantinga's - that for God to banish evil, he would also have to banish free will—are only marginally relevant. First, it addresses only logical, not metaphysical, necessity. Second, it's irrelevant for natural evil (hurricanes, tsunamis, etc) and for evil suffered by sentient but non-human animals. Third, it holds a naïvely realist view of free will, one that is arguably unjustified. For these reasons, any conventional panentheism is untenable.

But there remains a valid intuition here, I think: that there exists some kind of higher-order consciousness or mind in the universe. This, in fact, may be the one valid belief behind virtually every religion known to man. It has seemed plausible, even obvious, to many people over the millennia that some sort of Mind (or Minds) are at work in the cosmos. Given a vague analogy to the

1 For a good exploration of Krause's views, see Göcke 2018.

2 For sake of convenience, I will refer to God in terms of male pronouns; but this is not intended literally, of course. (To be politically correct, perhaps I should use a gender-neutral pronoun like >zie.< But I won't.)

3 There are no panentheistic religions, to my knowledge. 
human mind, it's natural to project anthropomorphic qualities onto this Mind. And even this has some rational basis, as I will argue. But to turn the Big Mind into an all-good, all-powerful God who loves each and every one of us, answers prayers, sends sinners to hell, etc - this won't do at all. What we need, then, is a naturalistic theology without the religion: a logos of theos (rationality about God) without the >binding $<$ (re-ligio, lit. to bind). I hope to make some progress along this path in the present essay.

\section{The Greek Context}

Having sketched some cursory thoughts on panpsychism, panentheism, God, and mind, I'd like to start to synthesize these concepts into a viable and naturalistic theology. Unsurprisingly, many important ideas on this front were first articulated by the Greeks. Let's remind ourselves what they said on these topics.

The pre-Socratics seemed quite convinced that the cosmos as a whole was ensouled in some way. Aristotle (411a7) tells us that Thales' view was of a psyche that was »mixed with the whole [cosmos].« Anaximenes is recorded as saying this: »Just as our psyche, being air, holds us together and controls us, so do breath and air surround the whole cosmos « (frag. 17). For Xenophanes, »God is one«; he »remains in the same place, moving not at all.« Yet this God somehow controls all: »Without effort he shakes all things by the thought of his mind « 4 Heraclitus' God is Logos, a kind of cosmic rationality. Logos is sthe Wise One, $>$ the Eternal One, $<$ and $>$ the Thunderbolt $<$ indeed, $\gg$ The Thunderbolt steers the Universe.« The Logos acts not from without, but from within: »The Wise One knows the plan by which everything is directed through everything « (frag. 41). Finally we have Anaxagoras, who posited Mind (nous) as his cosmic overseer: »Whatever things were to be, and whatever things were, as many as are now, and whatever things shall be, all these Mind arranged in order « (frag. 12). His view, according to Aristotle (984b15) was that »just as in animals, so in nature, Mind is present and responsible for the world.« Hence there seems to be a kind of pre-Socratic consensus that a divine intelligence pervades the universe, a cosmic Mind or cosmic Reason, which in some way moves things and brings order and coherence to all.

Such ideas were clearly seminal for Plato and Aristotle. Among many other things, Plato is famous for the first clear articulation of a world-soul. Two initial points here: First, as with his predecessors, >world $<$ and $>$ soul $<$ are kosmou (cosmos) and psyche. So the purported world-soul is best conceived of as a cosmic

4 Fragments 8, 10, 11. 
psyche or cosmic mind - a kind of rational intelligence. Aristotle confirms this for us: »it is evident that Plato means the soul of the whole to be like the sort of soul which is called mind « (De anima, 407a5).

Secondly, Plato explicitly differentiates the cosmic mind from the creator god or Demiurge. The latter brought the universe into being along with all its elements and then, in a separate act, it created the cosmic mind. But then the Demiurge vanishes from the scene, leaving the cosmic mind on its own. Notably, this mind is apparently unconcerned with the detailed operations of things, and especially unconcerned with human matters. Its main function seems to be to drive the regular motion of the heavenly bodies, and thus to »manage « the cosmos. ${ }^{5}$ It operates on the level of the whole, not the parts. In a very real sense, the cosmos is constructed on the same model as the human being; both have physical bodies and both possess higher-order rational minds. As above, so below.

Thus stated, it's a fairly clear conception of panentheism. The cosmos is a god because it is intelligent, divine, and ensouled. But this god creates nothing, is not moral, and certainly has nothing to do with individual humans. He doesn't answer prayers, condemn people to hell, or send his son down to Earth to save humanity—not even close. Plato's is a rational, philosophical panentheism.

Importantly, Plato seems to add a subtle form of panpsychism to his panentheistic ontology. Scattered throughout his late works are references to many kinds of ensouled things - and the list is impressively long. In addition to humans, animals, and the cosmos, he attributes psyche to plants (Tim $77 \mathrm{~b}$ ), individual bones (Tim 74e), the Earth (Tim 40c), stars (Tim 41e), the sun and moon (Laws 898d), the four elements »alone « (Laws 895c), and even to the sum total of reality (Soph 249a). What consistent metaphysics could allow such ensouled entities and yet not include everything? Plato's case for panpsychism is implicit but strong. And if we are still unconvinced, he seems to resolve the issue for us with a striking passage near the end of Laws:

Now consider all the stars and the moon and the years and the months and all the seasons ... A soul or souls ... have been shown to be the cause of all these phenomena, and whether it is by their living presence in matter ... or by some other means, we shall insist that these souls are gods. Can anybody admit all this and still put up with people who deny that »everything is full of gods«? (899b)

The last phrase recalls Thales' panpsychist proclamation. ${ }^{6}$

5 Laws (899a).

6 Nearly all the pre-Socratics were panpsychists; see Skrbina 2017. 
For his part, Aristotle follows many of these attributions of psyche, though with a different interpretation. Psyche, for him, was the form or structure of biologically living things. Thus only humans, animals, and plants are ensouled, in a technical sense. Even so, other things in nature possess remarkably soul-like or life-like qualities, he says. For one, all of matter exhibits a kind of upward striving, a yearning for completion, fulfillment, life, and psyche. As John Rist (1989: 123) explains, for Aristotle, »the whole of the cosmos is permeated by some kind of upward desire and aspiration. «We see this described explicitly in Physics (25ob12), where Aristotle writes of »an immortal never-failing property of things, « namely, »a sort of life, as it were, to all naturally constituted things." Elsewhere he explains that the four elements, individually, "possess a principle of movement in their own nature «. ${ }^{7}$ As well the cosmic sphere, because it displays constant and rational self-motion, is ensouled: »the heaven is animate and possesses a principle of movement ${ }^{8}{ }^{8}$ Stars, too, embody a psyche: »We think of the stars as mere bodies ... but we should rather conceive them as enjoying life and action; $\aleph^{9}$ after all, their movement »[is] similar to that of animals and plants.«

In his late writings Aristotle developed a notion of God as an Unmoved or Prime Mover, one who drives the motion of the cosmos via his thoughts. The Mover is thus a Mind; he thinks, and the universe revolves. $\gg$ Life also belongs to God; for the actuality (energeia) of thought is life, and God is that actuality, « he writes. ${ }^{10}$ Somewhat later in Metaphysics, he reiterates that $»$ these substances [i.e. stars] are gods, and that the divine encloses the whole of nature.« God, the cosmic Mind, thinks. Of what? Of itself: »Therefore it must be of itself that the divine thought thinks (since it is the most excellent of things), and its thinking is a thinking on thinking ${ }^{11}{ }^{11}$ As with Plato, we have here no moral God, no redeemer, no dealer in prayer and sacrifice. This God is utterly unconcerned with human affairs. He merely thinks, and his divine rationality maintains order in the cosmos.

Of this view of God as world-mind, Whitehead (1967: 173) was notably impressed. On this basis he grants Aristotle the title of "greatest metaphysician« in Western philosophy. Being largely free from mythological and theological baggage (of the Christian type), Aristotle could envision a purely rational

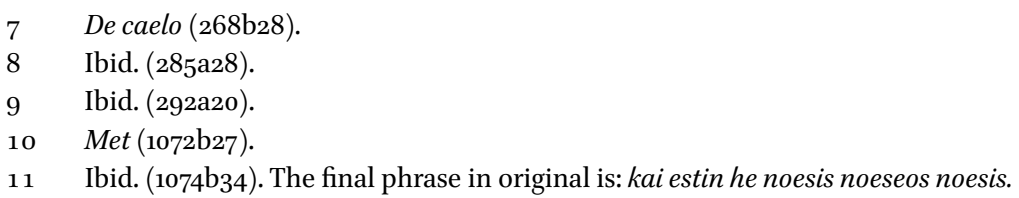


conception of God. For Whitehead, it's a kind of peak in conceptual thought, something perhaps unsurpassable: »It may be doubted whether any properly general metaphysics can ever get much further than Aristotle.«

But there is more to be said. Even a cosmic Mind cannot move things without some means-a carrier or conveyor of the mental force. In the heavens, according to Aristotle, this was accomplished via the so-called fifth element, ether. ${ }^{12}$ Ether conveys a circular motion from the Mind to the heavenly bodies. This suffices for the heavens, but ether does not exist (or at least is not efficacious) here on Earth. And none of the four traditional elements-fire, air, water, or earth-will do the job. Thus Aristotle was compelled to (re)introduce a new, Earthly element, the pneuma, that functioned like the ether. ${ }^{13}$ It had to be the carrier of mind, and to pervade all aspects of the earthly realm. He describes this strange entity variously as »the faculty of all kinds of psyche, « a »vital heat (thermoteta psychiken), and »the principle of psyche «. ${ }^{14}$ It is, he says, »analogous to the element of the stars « [i.e. the ether]. Permeating everything, pneuma thus effectively animates everything, at least indirectly. In one of the most stunning passages in the Aristotelian corpus, he writes the following:

Animals and plants come into being in earth and in liquid, because there is water in earth, and pneuma in water, and in all pneuma is vital heat, so that, in a sense, all things are full of psyche. ${ }^{15}$

So it's not that all things are ensouled - this applies only to biological life-but rather that a principle of psyche or vital heat pervades everything, filling them »in a sense « with soul. This is fully consistent with his earlier remark on the »sort of life« in all things. Via the pneuma, all of matter is thus quasi-animated. Hence we arrive at a tentative panpsychism in Aristotle, of the sort few would have expected.

As insightful as these two men were, both have shortcomings from our modern perspective. Plato comes across either as a double-dualist (body and soul, and matter and Form) or more likely as some kind of radical pluralist. He thus invites a range of interaction problems and a host of other difficult

12 Aristotle seems to be uncomfortable with the term >ether, $<$ given that he rarely calls it by name. More commonly he refers to it as the »primary body, «»first element, « or »element of the stars."

$13>$ Pneuma< was already an old concept by Aristotle's time.

$14 \quad G A(736 \mathrm{~b} 29-737 \mathrm{a} 8)$.

$15 G A(762 \mathrm{a} 18)$. 
metaphysical questions that go unanswered. Aristotle's cosmic Mind is more coherent and rational but we have a hard time fitting it into a larger conception of mind, especially given the strange and late introduction of the pneuma as a quasi-panpsychist entity.

Perhaps, then, we are best served by taking these ideas as inspiration and as aspects of truth in some broader metaphysical sense. Let me now try to construct a contemporary vision of God as a world-mind, vaguely along Greek lines, but with an eye to more recent ideas in philosophy of mind.

\section{First Philosophy of the Mind}

Pressing ahead: All philosophizing about the mind starts with one elemental fact, namely, that we ourselves are enminded and experiential beings. This is an old truth, dating back at least to Descartes, and it holds with full force today. There is no more indisputable truth than that we experience the world. Experiential reality exists, precisely because we are such reality. All serious philosophy must begin from this central metaphysical fact - perhaps the only indubitable fact that we possess.

Every move from here involves speculation, but we must try to keep it wellgrounded speculation. My experiences seem to be of two broad categories. On the one hand, I have the various qualitative feelings of sensory impressions and other internal mental states. Vibrant orange color, a piercing scream, and the smell of fresh bread all evoke qualitative feelings. These qualia are then attached to certain things in my surroundings, in an apparently causal way. But the feelings themselves reside in me.

On the other hand, my experiences seem to have a sense of directedness, of focus, and of deliberation. They are about things. This so-called intentional aspect of the mind manifests itself in different ways: as desire, as will, as cognition, as belief. These mental states are oriented at, or directed toward, certain conditions or states of being. I see something, I want something, I think about or believe in something.

These two categories are distinct but not independent. Many of my mental states - perhaps all —are a mixture of qualia and intentionality. Sensory impressions almost necessarily correlate with certain beliefs, for example, such as that a certain object is real and caused so-and-so sensory impression. My seeing and smelling a fresh loaf of bread is virtually simultaneous with my wanting a piece. A pleasing piece of music is connected to beliefs and thoughts about the composer. Feeling cold is connected to a belief about the need to 
close an open window, and so on. ${ }^{16}$ All this, then, arises from fundamental introspection. I am an experiential being, and my mental states seem to be composed of two distinct aspects: qualitative and intentional.

My next step is to direct my attention outward, to the world at large. Here I embrace ontological monism. Dualism and pluralism have a certain intuitive force, but the problems of interaction, and general principles of parsimony, argue against them. After all, we do seem to inhabit one world. There is one reality, as best we can tell. Its nature may be complex, but it nonetheless is still one kind of thing, with likely one essential nature. The same physicaland metaphysical-laws must hold throughout. Any other conception is highly problematic. Dualism, for example, not only introduces interactionist problems but is also, objectively speaking, arbitrary. Why two substances? And which two? Does >mind < and >matter $<$ really make sense as an ontological scheme, in this broad universe that we inhabit? Triple-ism (>triplism<? >trialism $<$ ?), quadruple-ism (>quadrism $<$ ?), etc are no less arbitrary. It seems that the only remotely viable alternative to monism is a radical pluralism - an infinity of substances; this at least has the virtue of being non-arbitrary. Perhaps we are back to Anaxagoras once again. ${ }^{17}$ But for now, at least, I set this option aside.

I take it, then, that the two primordial metaphysical facts are (1) that I am an experiential being with a dual-aspect mind, and (2) that reality is a monistic entity. Everything about that monistic reality is experiential—some aspects are sensory, some are cognitive, some are volitional, but all are experiential. The sum total of my encounter with the one reality is an assortment of experiential qualities. ${ }^{18}$

My next general observation about the world is that there seems to be a distinction between >me and >not-me<. Me-my mind, my self-seems to be spatially located in my head, thanks primarily to my sense organs (four of them, anyway) being located there. But I won't worry here about the problem of location. Me is indubitably real, the locus of my experiences. Not-me, the outside world, seems equally real, as the source of various stimuli. Not-me seems concrete, tangible, dynamic, interactive. As a result, I tend to assign all not-me a categorical label: physical. In fact, >physical may be defined as that

16 I hasten to note that this two-part categorization is not new. Leibniz seems to have established the basic idea in the »perceptions « and »appetites « of his monads-perception representing a qualitative perspective, and appetite (or desire) an intentional one.

17 Or maybe Spinoza, with his infinitely-many attributes of the one God/Nature.

18 Henryk Skolimowski developed a related view in his conception of >noetic monism. $<$ See Skolimowski 1994/2019. But he elected not to articulate the panpsychist implications of this view. 
portion of experiential reality that I experience as not-me. In more common terms, sthe physical seems to have a surface or exterior that I sense, and then perhaps something more, an interior, that I do not sense. In any case, sthe physical is a wholly experiential reality, just as myself is a wholly experiential reality.

Both seem equally real, and yet both seem different, distinct; but they cannot be ontologically distinct because reality is a monistic entity. The me/notme distinction must be one of appearance only, not reality. Or at least, not of fundamental reality. But the appearance itself, however, may well be a fundamental fact of existence.

The not-me is furthermore apparently distinguishable into two vague categories: like-me and unlike-me. Like-me includes other normally-functioning adult humans (and perhaps teens and children); unlike-me is everything else. The like-me's seem to operate in the world basically the same as I do, and seem to be constructed, as it were, on the same metaphysical plan. But of course, given a monistic reality, this must be true. Everything, even the unlike-me's, must be constructed on the same metaphysical plan.

Like me, the like-me's seem to have qualitative experiences, i.e. qualia. Like me, the like-me's seem to exhibit will, desire, cognition, and (generally speaking) intentionality. I thus have reason to believe that my experiential unity, and my dual-aspect mind, are universal qualities, at least among the like-me's. Again, this is to be expected on any monistic scheme.

But the apparent differences between me, like-me, and unlike-me must be explained as well. All are one, and all must share all essential characteristics. But because they are (apparently) distinct, they also differ in what we may call secondary characteristics. How can I tell the difference between essential and secondary characteristics? This is the major question at hand. If anything is to be considered essential, it must be the most fundamental facts of existence: namely, that each thing is an experiential being with a dual-aspect mind, and that each experiences the world as a monistic reality. Each thing must comprehend the world as a locus of experiences that it has.

If things have a further characteristic, it must be the ability to distinguish between >me $<$ and >not-me $<$; in other words, a sense of self. Assuredly all animals possess this, and likely all plants. Whether this distinction moves beyond biological life is difficult to say. But the sheer fact that things function in the world as distinct units, as integrated wholes, suggests that they do-in proportion to the intensity of their integration. Rocks are relatively strongly integrated, as are atoms and molecules. These things likely realize the me/not-me distinction, if only in very rudimentary form. Less integrated things_-clouds, societies, solar systems - likely have only a correspondingly vague (and rudimentary) sense 
of self. Again, this is not a problem because the me/not-me distinction is not ontologically fundamental. It's a question of degree. But as I said, the appearance of a distinction may well be fundamental.

This raises an important issue because objecthood is vague; it too is a question of degree. If we allow, for example, that there are ultimate particles, then we are inclined to agree with Democritus: only atoms and the void. All socalled objects are mere appearances. But the atoms collect into quasi-stable patterns, and then into patterns of patterns, and then patterns of patterns of patterns, and so on. These patterns come to be called objects. And we ourselves are precisely one such pattern. Yet we are not mere appearance; we are real, efficacious beings. Other objects are the same. Here we part company with Democritus; objects have a concrete status in the world.

Degree of objecthood must correlate with degree of unity, in some sense, which in turn correlates with degree of subjecthood. On this view, each object, no matter how conceived, is a subject - to a greater or lesser degree. If each object is a subject, we then arrive at a strong form of panpsychism, as I suggested at the outset.

\section{Mind, Both Lesser and Greater}

The only mind that we know directly is our own. Being relatively intenselyconstructed objects, we have a relatively intense form of subjecthood. Intensity is a function of several factors: stability, coherence, dynamism, and complexity. Mental intensity, correspondingly, has its factors: focus or coherence, energy, subtlety, and sensitivity. If physical and mental states are the two counterparts of one reality, then each must correlate with the other, on a one-to-one basis. Each object is a subject, and thus each physical change is at once a mental change. Physical state and mental state are two sides of the same (monistic) coin.

Our bodies, and in particular our brains, are quasi-stable patterns of (say) particles or quanta of energy that maintain consistent, multi-layered patterns of dynamic interaction over several decades. This is reflected in our semistable memories and personality. Therefore we possess correspondingly coherent, sensitive, and subtle minds that persist over time. An equally-massive rock is more stable but less dynamic, and hence is expected to have a less intense, if more durable, mental unity. A star like the sun is more massive, more energetic, and more stable of a pattern, and yet its structural complexity is far below that of a human being. The experiential unity of the sun will be at once more energetic and yet simpler and less intense than the human mind. 
By contrast, consider human artifacts such as computers. Modern integrated circuits are much more complex than our brains. The brain contains something like 500,000 neurons per square millimeter, but new computer technology is producing up to 100 million transistors per square millimeter. ${ }^{19}$ Single chip processors now hold up to 19 billion transistors. The experiential unity of a CPU chip is thus likely more intense, if less energetic, than that of a human. Such technologies will serve as the basis of advanced artificial general intelligences that will soon exceed our own capacities.

An object, then, is simply a more or less well-integrated pattern of energy. The more integrated patterns have a more coherent mental unity; the less integrated, a less coherent one. But the central point, once again, is this: Every object is a subject. Or more compactly: each is an ob/sub.

Every object can also be thought of an aggregate-there being no ontological distinction between the two. A rock is an aggregate, a plant is an aggregate, a human is an aggregate, a star is an aggregate. The more obvious aggregates, like a solar system, a football team, or a heap of sand, are also objects, though less well-integrated. They are also, correspondingly, less well-integrated subjects; but they are subjects nonetheless.

This being the case, it implies that every aggregate - that is, every combination of elements or individual objects-is also an object in its own right, and thus also a subject in its own right. Or: every aggregate is an ob/sub. Even the most bizarre aggregates, like the one composed of my chair, the moon, and an atom in some faraway galaxy, is an object, and thus also a subject. But such ob/subs are of such low intensity that they are utterly indistinguishable from the background patterns of energy in the universe. They have conceptual importance but no practical relevance. The functionally relevant ob/subs are those >ordinary < things that we distinguish in the world around us-rocks and trees, stars and planets, tables and chairs. They have persistent coherence and relatively strong degrees of integration, and thus play a dominantly causal role in the world.

Under this conception, the world is a vast entanglement of enminded $\mathrm{ob} /$ subs. Every apparently discrete thing is an ob/sub in itself, and is at the same time a participant in countless diversified ob/subs. Again, nearly all of the diverse objects, including the more bizarre combinations, fade into insignificance, both as physical objects and as enminded subjects. The ones that really >count $<$ are those things that we naturally pick out as discrete entitiespeople, animals, plants, rocks, artifacts, planets, stars. They are the most

19 A neuron is a biological >decision element $<$ which functions, loosely, like a single transistor. The analogy is rough but will suffice for present purposes. 
articulated objects, and hence the most articulated subjects. In fact, this is precisely why we pick them out — our minds are recognizing and relating to other, comparably-distinct minds (albeit in the form of objects).

Thus understood, ob/subs extend down to the smallest quanta of energy and up to the large cosmic structures-including, importantly, the cosmos as a whole. It would not be far from the mark to declare the vast interconnected web of ob/subs as the effective fabric of reality. In this web, the complexity and intensity of minds vary accordingly, but they all share the essential characteristics. Each is an experiential being, an experiential unity, with a dual-aspect mind; each experiences the world as a monistic reality; and each has a sense of selfhood. »All mind is alike, both the lesser and the greater« (Anaxagoras).

\section{God as World-Mind}

If all objects are subjects, and all subjects share certain core qualities (an experiential, dual-aspect mind; a sense of monism; a me/not-me distinction), then, at the highest level, the level of the cosmos as a whole, we may infer the existence and nature of a cosmic Subject, a cosmic Mind-God. The Mind of God must be constructed on the same metaphysical plan as the human mind, and as the mind of an atom. »As above, so below.« »All mind is alike.« Macrocosm and microcosm. Perhaps there is some wisdom in these old hermetic ideas after all-ideas that appear to date back to Pythagoras, at least.

If »all mind is alike, « then the Mind of God must function essentially in the same manner as our minds. That is, it must (a) be an experiential being, possessing a dual-aspect mind; (b) experience reality as a unified whole; and (c) possess a sense of self. Of this last point, God's sense of self would seem to be utterly unique because, for him alone, all is >me,< and there is no >not-me.< What must it be like, for all to be oneself? For all to be $m e$ ? We can scarcely imagine.

Furthermore, the relation of God to the universe must be analogous to that of our minds to our bodies. And what is that? Do we have panenthestic minds? Decidedly not. Minds are not souls — not in any modern sense. Our minds are not >in $<$ our bodies. Without pretending to solve all mind-body problems, I think we can plausibly claim that the mind and body are fundamentally interconnected - two aspects of the one monistic substance, which is none other than reality itself. There is no causal link between mind and body, in either direction; this is impossible in any truly monistic universe.

Our minds do not cause our bodies to do things. Assuming that there is causal interaction in an experiential cosmos, then it is between the various 
$\mathrm{ob} /$ subs. As a given ob/sub changes its internal configuration through interaction with other ob/subs, its physico-mental state changes as well. I step barefooted on a sharp rock; my foot suffers a momentary deformation; and my bodily mental state (and eventually my conscious state) changes accordingly. The small time delay for any conscious effect is not relevant in this ontological scheme; it's a function of the spatial distance of my foot from my brain, and of the processing and signal transfer time in the cortex. In reality, so-called physical change and mental change are simultaneous. Every change in physical state is a change in a mental state. All things are ob/subs, and the universe is a monistic reality.

Correspondingly, God does not >do< anything in the cosmos. He cannot do anything because, as the Mind of the cosmos, he has no causal relation to it. Nor can it affect him in any way. God's only function and purpose is to instantiate the ever-changing experiential state of the universe. Rather as Aristotle said, he simply thinks. Unlike Aristotle, he doesn't drive the rotation of the heavens, not even by not moving. Rather, God's mental state is the >rotation of the heavens, $<$ manifest as an experiential unity. Every physical change in the universe has a corresponding change in God's mental state. Every small action I take-picking up my tea cup-and every small movement in nature-the rustling of leaves in the slightest breeze-are reflected in God's mind. In this sense, God knows all. We can legitimately say that God is omniscient.

But he cannot do anything with this knowledge. Not only is he not omnipotent, he has, as I said, no power at all. God is utterly power-less. He cannot interfere with human affairs; cannot answer prayers; cannot invoke miracles; cannot condemn people to hell — nothing. He is powerless to stop evil, to cause evil, or anything else. God simply thinks; he experiences.

Is God all-good? Compare to this question: Is our own mind ‘good`? These are normative questions that do not pertain to metaphysics. God, like our own minds, is neither good nor bad, simply because such terms are not predicable of minds. Minds simply are. They exist. They are the fabric of reality.

As the mind of the whole, God encompasses all layers of sub-mind within the cosmos. Just as all lesser objects are parts of the cosmic Object, so all lesser minds are parts of the cosmic Mind. In an experiential cosmos, God is the great Experiencer. God's Mind is the sum total of all mind. In this sense, my metaphysical view may qualify as a form of pantheism: all is mind, and all mind is a portion of God's Mind. All is God.

Such a God is, again, but a faint image of any traditionally religious God. God thinks, he experiences; nothing more. Then why call him God at all? What do we mean, in fact, by the term >God $\ll$ ? Etymology is not much help. `God 
seems to derive from the proto-Indo-European ghut (>that which is invoked $<$ ) or perhaps from ghu-to (>poured, < as in a libation or ceremonial drink). But these origins are hopelessly vague. Standard religious interpretations are not much better, given the vast diversity of meanings and characteristics attributed to God, amongst the 4,00o or so world religions.

And yet there seems to be a core conception of God that we can distill from the many interpretations. There appear to be two qualities that are shared by virtually all traditional conceptions of God. These are, first, that God is a kind of supreme being or ultimate reality. As the cosmic Mind, the God I have articulated here would indeed qualify as supreme and ultimate. The second core quality is that God is that thing which is most revered. Ought we to revere God, the cosmic Mind? Certainly we need not pray to him, which would be both pointless and inconsequential. But we might do well to develop a sense of awe and wonder at the cosmic Mind, and at our own small participation in it. Such an outlook certainly casts humanity in a new light, vis a vis the broader cosmos from which we evolved, and of which we belong.

And how, in fact, are we even to know such a God at all? How can we hold him in awe and wonder if we cannot truly know him? Here we might do well to recall Plato and his discussion of the soul of the sun. Plato, too, was concerned that we grasp the sun's soul even though it is utterly invisible to us, in any conventional sense. In his final work Laws, he wrote:

Everyone can see [the sun's] body, but no one can see its soul—not that you could see the soul of any other creature, living or dying. Nevertheless, there are good grounds for believing that we are in fact held in the embrace of some such thing, though it is totally below the level of our bodily senses, and is perceptible by reason alone. $(898 \mathrm{~d})$

When the sun shines down upon us, bathing us in his glory, we are, says Plato, »held in his embrace.« His soul is there, it is real, it exists; though, like everyone's soul, we cannot perceive it but by rational thought. In this sense, we perceive the mind only with the mind. Of course-how could it be otherwise?

In the same way, then, we may think about the Mind of the whole, God. We cannot see it, cannot hear it, cannot sense it in any way. And yet, by careful rational thought and well-ground speculation, we can understand that it may be there, that it must be there- that the Mind of God is as extant and real as our own mind. A rational God, a philosophical God, an omniscient God, a God that demands no subservience and that smites no sinners. Indeed-a God for whom no one need suffer and die at all. Imagine: a God for all humanity and for all time, yes, a God for all the universe. Imagine. 


\section{References}

Göcke, B. (2018) The Panentheism of Karl Christian Friedrich Krause (1781-1832). Peter Lang.

Rist, J. (1989) The Mind of Aristotle. Phoenix series, vol. 25. University of Toronto Press. Skolimowski, H. (1994/2019) The Participatory Mind. Creative Fire Press.

Skrbina, D. (2017) Panpsychism in the West (revised ed.). MIT Press.

Whitehead, A. (1967) Science and the Modern World. Free Press. 